\title{
Probing myocardial blood oxygenation reserve with controlled hypercapnia using BOLD CMR
}

Hsin-Jung Yang ${ }^{1,2^{*}}$, Roya Yumul ${ }^{1,3}$, Richard Tang ${ }^{1}$, Ivan Cokic ${ }^{1}$, Michael Klein ${ }^{5}$, Avinash Kali', Olivia Sobczyk ${ }^{4}$, Behzad Sharif ${ }^{1}$, Jun Tang ${ }^{1}$, Xiaoming Bi ${ }^{7}$, Sotirios A Tsaftaris ${ }^{6}$, Debiao Li $^{1}$, James K Min ${ }^{1}$, Daniel S Berman ${ }^{1}$, Antionio Hernandez Conte ${ }^{1}$, Joseph A Fisher ${ }^{4,5}$, Rohan Dharmakumar ${ }^{1}$

From 17th Annual SCMR Scientific Sessions

New Orleans, LA, USA. 16-19 January 2014

\section{Background}

Background More than half of the cardiac stress tests require pharmacologic vasodilators for induction of hyperemia to assess myocardial perfusion, but carry the potential for side effects and are contraindicated in many patients considered for testing. We evaluated the feasibility of a non-invasive and safe stress-testing paradigm using a precisely targeted partial pressure of arter- ial $\mathrm{CO} 2(\mathrm{PaCO} 2)$ to induce myocardial hyperemia, and compared this response to intravenous adenosine.

\section{Methods}

Dose-response studies were performed on spontaneously breathing humans $(\mathrm{n}=18)$, and canines $(\mathrm{n}=18)$ with and without surgically implemented coronary stenosis to determine the optimal increase in $\mathrm{PaCO} 2$ required to
A

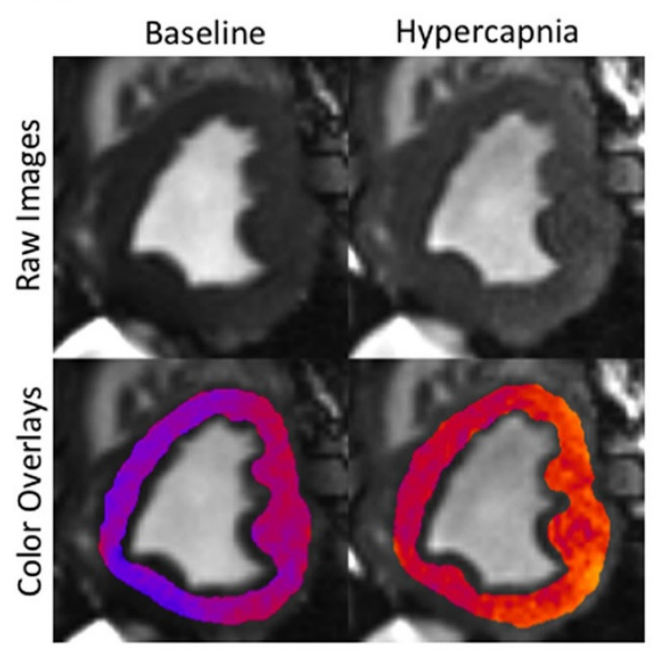

B

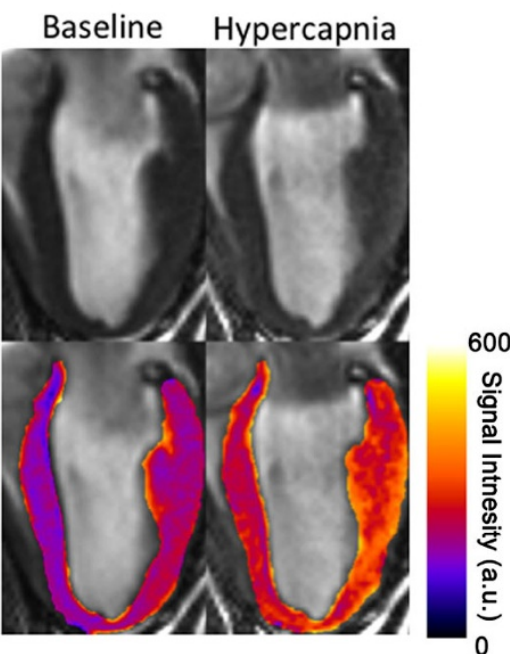

Figure 1 Effect of changing arterial CO2 on BOLD CMR signal intensities. Representative short (A) and long (B) axis BOLD CMR images collected from a canine from Group Ramp under baseline (PETCO2 $=42 \mathrm{mmHg}$ ) and hypercapnia (PETCO2 = $55 \mathrm{mmHg}$ ) are shown. Note the increase in signal intensity in images under hypercapnia relative to baseline.

${ }^{1}$ Cedars Sinai Medical Center, Los Angeles, California, USA

Full list of author information is available at the end of the article 


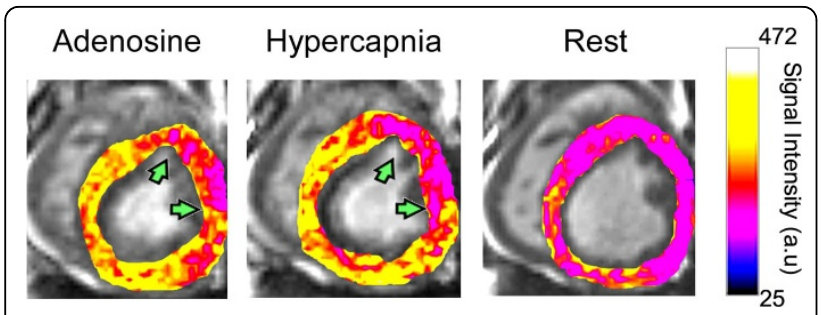

Figure 2 BOLD CMR-based evaluation of adenosine versus hypercapnia in the presence of LAD stenosis in canines.

Representative color-overlaid BOLD CMR images acquired during adenosine infusion, hypercapnia, and rest from a canine with a significant narrowing of LAD. Color bar shows BOLD CMR signal intensity. Images acquired under adenosine infusion and at rest were obtained under normocapnia.

replicate the hyperemic response to intravenous adenosine $(140 \mu \mathrm{g} / \mathrm{kg} / \mathrm{min})$. Blood-Oxygen-Level-Dependent (BOLD) CMR was used to determine the effects of hypercapnea.

\section{Results}

In humans, an increase in $\mathrm{PaCO} 2$ of $10 \mathrm{mmHg}$ was well tolerated, and the BOLD CMR responses were similar to those due to standard adenosine $(\mathrm{p}=0.7)$. In intact canines, the BOLD response to a mean increase in $\mathrm{PaCO} 2$ of $11 \mathrm{mmHg}$ was similar to that of adenosine infusion $(140 \mu \mathrm{g} / \mathrm{kg} / \mathrm{min}, \mathrm{p}=0.4)$; the responses were also similar in the territories subtended by stenotic $(\mathrm{p}=$ $0.7)$ vessels.

\section{Conclusions}

Conclusion Targeted increases in $\mathrm{PaCO} 2$ of $10 \mathrm{mmHg}$ is well tolerated and has a myocardial vasodilating effect similar in extent to that of adenosine. These findings support continued investigation into the feasibility of inhaled $\mathrm{CO} 2$ as a vasodilator for cardiac stress testing.

\section{Funding}

National Heart, Lung, And Blood Institute (HL091989)

\section{Authors' details}

${ }^{1}$ Cedars Sinai Medical Center, Los Angeles, California, USA. ${ }^{2}$ Bioengineering, University of California, Los Angeles, Los Angeles, California, USA.

${ }^{3}$ Anesthesiology, University of California, Los Angeles, Los Angeles, California, USA. ${ }^{4}$ Physiology, University of Toronto, Toronto, Ontario, Canada.

${ }^{5}$ Anesthesiology, University of Toronto, Toronto, Ontario, Canada. ${ }^{6}$ IMT institute for advanced studies lucca, Lucca, Italy. ${ }^{7}$ Siemens Medical Solusions, Chicago, Illinois, USA.

Published: 16 January 2014

\section{doi:10.1186/1532-429X-16-S1-014}

Cite this article as: Yang et al:: Probing myocardial blood oxygenation reserve with controlled hypercapnia using BOLD CMR. Journal of

Cardiovascular Magnetic Resonance 2014 16(Suppl 1):O14.

\section{Submit your next manuscript to BioMed Central} and take full advantage of:

- Convenient online submission

- Thorough peer review

- No space constraints or color figure charges

- Immediate publication on acceptance

- Inclusion in PubMed, CAS, Scopus and Google Scholar

- Research which is freely available for redistribution
C Biomed Central 